\title{
Growth stimulation of Clostridium butyricum in the presence of Lactobacillus brevis JL16 and Lactobacillus parabuchneri MH44
}

\author{
Jae-Seong $\mathrm{SO}^{1}$, Kyeongseok $\mathrm{OH}^{2 *}$ (D), YuJin $\mathrm{SHIN}^{1,3 *}$
}

\begin{abstract}
Certain strains of Clostridium butyricum exhibit characteristics of probiotics that are now sold in eastern Asian countries such as Korea and Japan. Integral improvement in C. butyricum functions can be achieved in the presence of Lactobacillus spp. through the process of attentive selection. This study aimed to select specific strains of lactic acid bacteria that could synergistically enhance the probiotic functions of $C$. butyricum. The supernatants of 249 lactic acid bacteria were examined, and we observed that 24 strains did not inhibit the growth of C. butyricum. Additionally, 4 of these 24 strains induced over 2 -fold promotion in C. butyricum growth rates during co-culture with this bacterial strain. This growth promotion was verified using qPCR. In particular, Lactobacillus brevis JL16 and Lactobacillus parabuchneri MH44 stimulated C. butyricum more effectively than did other strains. We determined the level of buk (butyrate kinase) expression, the survival rate in the presence of bile salt, the ability of auto-aggregation, and the survival rate after freeze-drying.
\end{abstract}

Keywords: Clostridium butyricum; butyric acid; probiotics; Lactobacillus spp.; co-culture.

Practical Application: Co-culture of C. butyricum with Lactobacillus strains and its application to growth stimulation.

\section{Introduction}

Optimal candidates for market probiotics must exhibit the ability to undergo affordable fermentation and cost-effective separation. Probiotics should also possess characteristics that make them suitable for healthcare purposes. Although a large number of research papers have claimed various efficacies, a clear mechanism underlying the functions of these probiotics has not been confirmed. Among the probiotics, Clostridium butyricum is a particularly notable probiotic species. C. butyricum is an anaerobic bacterium and strengthens the immune system and decreases the number of pathogenic bacteria, thus indicating that C. butyricum possesses the potential for future use as a probiotic (Takahashi et al., 2004; Yasueda et al., 2016; Kong et al., 2011). In previous studies, Clostridium spp. (Clostridium botulinum, Clostridium diffile, Clostridium tetani, etc.) were demonstrated to act as pathogenic bacteria that generate toxic chemicals that disturb the nervous system in mammals However, some strains of $C$. butyricum were adequately regarded as possible probiotics, as the capability and safety of $C$. butyricum have both been validated. In Asia, promising clinical results indicated that C. butyricum (MIYAIRI 588) could be useful for curing inflammation or diarrhea caused by antibiotic treatment, and this bacterial strain did not cause any significant side-effects during treatment (Yasueda et al., 2016). C. butyricum produces butyric acid (butyrate), which is a short-chain fatty acid that exerts various functions in the body. Butyrate is a major energy source for epithelial cells and helps epithelial cells to multiply to reduce intestinal damage and permeability and also accelerates anti-inflammatory effects (Kong et al., 2011). Additionally, butyrate has been reported to alleviate intestinal disease and to prevent metabolic syndrome. Patients suffering from intestinal diseases are known to generate less butyrate due to a reduction in the number of C. butyricum within the intestine (Rivera-Chávez et al., 2016). It must be noted that the interactions between intestinal microorganisms and the brain nervous system are affected by several types of interference that originate from the endocrine system, nerve system, and cell immune signal system. For example, the metabolic chemicals generated from microorganisms can act as signal molecules in the brain (Stilling et al. 2016). As a type of signal molecule, butyrate has been evaluated as an adjuvant therapy to treat vascular dementia (Liu et al., 2015), ischemic stroke (Sun et al., 2016), and depression (Hsiao et al., 2013; Tian et al., 2019). In animal tests, C. butyricum in combination with Lactobacillus spp. or other probiotics improved some of these factors in the animals. When C. butyricum was examined in chickens, it aided in the maturation and growth of beneficial probiotics when it was fed with Bacillus subtilis and L. acidophilus (Phuoc and Jamikorn, 2017).

In this study, we screened potential probiotic lactic acid bacteria (LAB) that could enhance the probiotic functions of C. butyricum. First, the growth of C. butyricum was evaluated in the presence of LAB (249 strains). To confirm the effect of co-culture with $\mathrm{LAB}$ on butyrate production by C. butyricum, we quantified the expression of buk gene. The buk gene is known to play an important role in the pathway of butyrate in C. butyricum. To evaluate the probiotic characteristics of the 
selected LAB, we examined bile resistance, auto-aggregation, and resistance to the freeze-drying process. The discussion was followed in regards to the stimulating growth of $C$. butyricum in the presence of candidate LAB strains.

\section{Materials and methods}

\subsection{Bacterial strains and growth conditions}

We obtained collections of LAB isolated from Korean women in 2001 (83 strains) and 166 strains isolated from fish and shellfish in the West Sea between 2008 and 2019 (Lee et al., 2010; Kang et al., 2016). The collected LAB were grown in MRS broth at $35^{\circ} \mathrm{C}$ under non-shaken conditions, and they were then maintained in $10 \%$ skim milk and stored at $-80^{\circ} \mathrm{C}$. C. butyricum KCTC1786 was obtained from the Korean Culture Center of Microorganisms and incubated on Reinforced Clostridium medium (RCM; Merck, Darmstadt, Germany) agar and Brain-Heart Infusion (BHI; Bacto, Spark, USA) broth at 35 ${ }^{\circ} \mathrm{C}$ under anaerobic conditions.

\subsection{Stimulation of C. butyricum with supernatants from Lactic acid bacteria}

Pre-cultured media were further cultured for one day after inoculation. Inoculation was controlled to $2 \%$ by adjusting the value of $\mathrm{OD}_{600}=1$ (optical density at $600 \mathrm{~nm}$ ). Supernatants were filtered to remove the cell of LAB using $0.2 \mu \mathrm{m}$ filter paper. C. butyricum was inoculated after mixing a LAB supernatant at a ratio of 7:3 and cultured in an anaerobic chamber. The value for OD and the number of strains were both determined to evaluate the growth rate. For comparison, MRS and BHI broths were added separately and compared using the same procedure.

\subsection{Stimulation of C. butyricum with cell of Lactic acid bacteria}

Equally measured numbers $\left(10^{6} \mathrm{CFU} / \mathrm{mL}\right)$ of Lactobacillus and C. butyricum were mixed and cultured for $24 \mathrm{~h}$ in an anaerobic chamber. Dilution of LAB was also used when different ratios of these mixtures (1:1 and 1:0.2) were needed. Quantification of C. butyricum was performed by analyzing the $s p o 0 \mathrm{~A}$ gene and by qPCR. Absolute quantification was recorded according to a standard curve by determining the qPCR Nano drop DS-11 (Denovix, Wilmington, DE, USA). The plate count method was employed to count the number of LAB present in MRS broth.

\subsection{Quantification of buk gene expression}

Gene expression and real productivity were determined to evaluate the number of C. butyricum and the concentration of butyrate. Specimens were prepared using the Tissue Total RNA Purification Mini Kit (Favogen, Ping-Tung, Taiwan). A DNase I solution was used to remove genomic DNA. Extracted RNA was assayed using a Nanodrop DS-11. cDNA was synthesized using the AMPIGENETM cDNA Synthesis kit (Enzo, NY, USA). Relative quantification of qPCR results was performed using BioRAD CFX96 (BioRAD, Hercules, CA, USA).

\subsection{Acid and bile resistances}

Acid resistance was determined in phosphate buffered saline (PBS) solutions at different $\mathrm{pH}$ values $(\mathrm{pH} 2.5,3$, and 7) that were adjusted using $5 \mathrm{M} \mathrm{HCl}$. LAB were cultured overnight and then centrifuged at $4,045 \mathrm{x}$ g for $5 \mathrm{~min}$. This was followed by washing and then inoculation using $10 \%$ sample after dilution to $10^{8} \mathrm{CFU} / \mathrm{mL}$. Bacterial enumeration was performed after $1 \mathrm{~h}$ of culture at $37^{\circ} \mathrm{C}$. MRS broths containing $0,0.3$, and $1 \%(\mathrm{w} / \mathrm{v})$ of Oxgall (Difco, Sparks, MD, USA) were prepared for the bile resistance test. Inoculation was controlled to $2 \%$ of the strains $\left(\mathrm{OD}_{600}=1.0\right)$. Viable cell count was obtained by plate counting after a $24 \mathrm{~h}$ culture at $37^{\circ} \mathrm{C}$.

\subsection{Auto-aggregation}

As previously proposed in the literature (Kos et al., 2003), we used a modified auto-aggregation test to evaluate the indirect adhesive property between cells. Cultured LAB were centrifuged at $4,045 \mathrm{xg}\left(5 \mathrm{~min}\right.$ at $\left.4{ }^{\circ} \mathrm{C}\right)$ and then washed before being suspended in PBS ( $\left.\mathrm{pH} 7.2, \mathrm{OD}_{600}=1\right)$. Auto-aggregation activity was calculated using Equation 1.

Auto-aggregation $(\%)=\left(1-\frac{A_{t}}{A_{0}}\right) \times 100$

Here, $A_{0}$ is the initial value of $\mathrm{OD}$, and $A_{t}$ is the determined value after 1,3 , and $5 \mathrm{~h}$.

\subsection{Freeze-drying stress resistance}

Skim milk was used to determine the resistance to freezedrying stress. It is established that skim milk can play an important role in protecting live cells during freeze-stress testing. Cultured strains were washed and suspended completely in PBS, and they were then mixed with $20 \%$ skim milk at a ratio of 1:1. Bacterial enumeration was performed after the drying process was complete. The viable cell counts were compared between the cases before and after the freeze-drying process.

\section{Results}

\subsection{Stimulation of C. butyricum growth by lactic acid bacteria}

C. butyricum was cultured in the presence of 249 different $L A B$ supernatants, and the results of $O D$ values were presented in Table 1. Among 249 LAB supernatants, 24 LAB supernatants showed the positive result of C. butyricum growth. In Figure 1, the increase of viable cells C. butyricum as well as OD values were presented. For contrast, MRS and BHI were included instead of LAB supernatant.

qPCR was employed to verify the effectiveness of co-cultures of C. butyricum and the LAB strains. Figure 2 presents the growth level and indirect results of gene expression when C. butyricum were co-cultured with selected $24 \mathrm{LAB}$. It is known that the spo0A gene induces spore formation only in C. butyricum and not in LAB. It was speculated that qPCR-based quantification could provide clues regarding C. butyricum growth, as the copy level of the $\$ p o 0 \mathrm{~A}$ gene is proportional to the concentration of 
Original Article

So; Oh; Shin

Table 1. Optical Density of C. butyricum with supernatant of lactic acid bacteria.

\begin{tabular}{|c|c|c|c|c|c|c|c|c|c|c|c|c|c|c|c|c|c|}
\hline Strain & OD & Strain & OD & Strain & OD & Strain & OD & Strain & OD & Strain & OD & Strain & OD & Strain & OD & Strain & OD \\
\hline KLB13 & - & KLB227 & - & KLB265 & - & HL 2 & - & HL 34 & - & JL29 & - & MH71 & - & QL9 & - & ML28 & - \\
\hline KLB14 & - & KLB228 & - & KLB266 & - & HL 3 & + & HL 36 & - & JL30 & + & MH74 & - & QL10 & - & YJ1 & - \\
\hline KLB30 & - & KLB229 & - & KLB267 & - & HL 4 & - & JL1 & - & JL31 & - & MH92 & - & QL11 & - & YJ2 & - \\
\hline KLB58 & - & KLB230 & - & KLB268 & - & HL 7 & + & JL2 & - & JL32 & - & D1 & - & QL12 & - & $\mathrm{YJ} 3$ & - \\
\hline KLB62 & - & KLB231 & - & KLB270 & - & HL 8 & - & JL3 & - & JL33 & - & D3 & - & ML1 & - & YJ4 & - \\
\hline KLB63 & - & KLB233 & - & KLB271 & - & HL 9 & - & JL4 & - & JL34 & - & $\mathrm{D} 4$ & - & ML3 & - & YJ5 & + \\
\hline KLB68 & - & KLB234 & - & KLB272 & - & HL 10 & - & JL5 & - & YG1 & + & D5 & - & ML4 & - & YJ6 & - \\
\hline KLB79 & - & KLB235 & - & KLB277 & - & HL 11 & - & JL7 & - & YG2 & + & D6 & - & ML5 & - & YJ7 & - \\
\hline KLB100 & - & KLB236 & - & KLB279 & - & HL 12 & - & JL8 & - & YG3 & - & M1 & - & ML6 & - & YJ8 & - \\
\hline KLB101 & - & KLB237 & - & KLB281 & - & HL 13 & - & JL9 & - & YG4 & - & M3 & - & ML7 & - & YJ9 & - \\
\hline KLB103 & - & KLB239 & - & KLB282 & - & HL 14 & - & JL10 & - & YG5 & - & M4 & - & ML8 & - & YJ10 & - \\
\hline KLB201 & + & KLB240 & + & KLB283 & - & HL 15 & - & JL11 & - & YG6 & + & M5 & - & ML10 & - & YJ11 & - \\
\hline eKLB202 & - & KLB241 & - & KLB285 & + & HL 16 & + & JL12 & - & MH5 & - & M6 & - & ML11 & - & YJ12 & - \\
\hline KLB203 & - & KLB242 & - & KLB286 & - & HL 17 & + & JL13 & - & MH6 & - & M7 & - & ML12 & - & YJ13 & - \\
\hline KLB207 & - & KLB243 & - & KLB287 & - & HL 18 & - & JL14 & - & MH8 & - & $\mathrm{O} 1$ & - & ML13 & - & YJ14 & - \\
\hline KLB209 & - & KLB244 & - & KLB288 & - & HL 19 & - & JL15 & + & MH15 & - & S6 & - & ML14 & - & YJ15 & - \\
\hline KLB210 & - & KLB245 & - & KLB289 & - & HL 20 & - & JL16 & + & MH19 & - & S7 & - & ML15 & - & YJ16 & - \\
\hline KLB212 & - & KLB246 & - & KLB290 & - & HL 21 & - & JL17 & - & MH21 & + & $\mathrm{T} 1$ & - & ML16 & - & YJ17 & - \\
\hline KLB213 & - & KLB247 & + & KLB292 & - & HL 22 & - & JL18 & - & MH22 & - & $\mathrm{T} 2$ & - & ML17 & - & YJ18 & - \\
\hline KLB214 & - & KLB248 & - & KLB293 & - & HL 23 & - & JL19 & - & MH33 & + & T3 & - & ML18 & - & YJ19 & - \\
\hline KLB215 & - & KLB249 & - & KLB294 & - & HL 25 & + & JL21 & - & MH44 & + & $\mathrm{T} 4$ & - & ML19 & - & YJ20 & - \\
\hline KLB217 & - & KLB251 & - & KLB295 & - & HL 26 & - & JL22 & - & MH49 & - & QL1 & - & ML20 & - & YJ21 & - \\
\hline KLB218 & - & KLB254 & - & KLB296 & - & HL 27 & - & JL23 & - & MH51 & - & QL2 & - & ML21 & - & JY1 & - \\
\hline KLB219 & - & KLB258 & - & KLB298 & - & HL 28 & - & JL24 & - & MH53 & - & QL3 & + & ML22 & - & JY2 & - \\
\hline KLB220 & - & KLB260 & - & KLB300 & - & HL 29 & - & JL25 & - & MH55 & - & QL5 & - & ML23 & - & JY3 & - \\
\hline KLB221 & - & KLB261 & - & KLB302 & - & HL 31 & - & JL26 & - & MH58 & - & QL6 & + & ML25 & - & & \\
\hline KLB224 & - & KLB262 & - & KLB306 & - & HL 32 & - & JL27 & - & MH62 & - & QL7 & + & ML26 & + & & \\
\hline KLB225 & - & KLB263 & - & HL 1 & + & HL 33 & - & JL28 & - & MH67 & - & QL8 & - & ML27 & - & & \\
\hline
\end{tabular}

+: higher OD values that determined to the effective growth of C. butyricum; -: Compared to ' + ', not effective growth of C. butyricum.

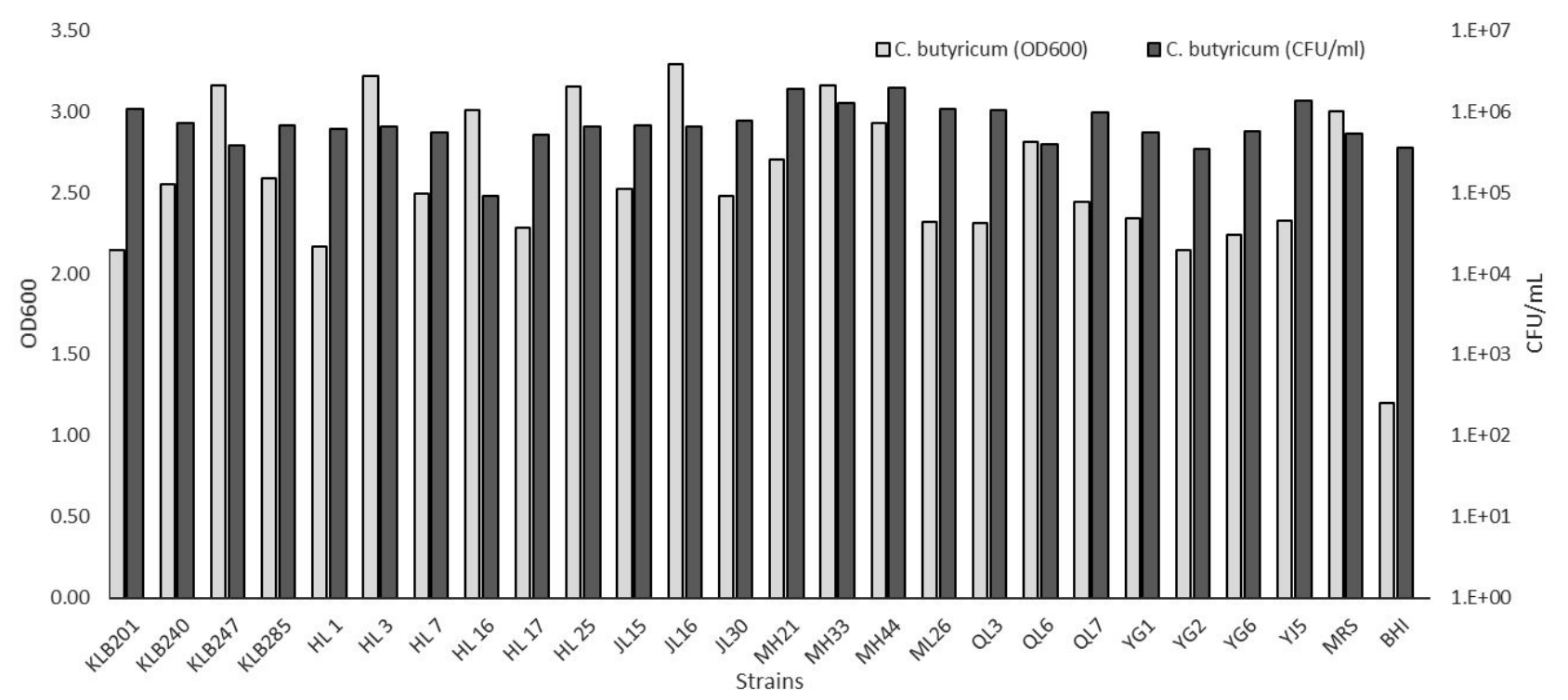

Figure 1. Growth of C. butyricum co-cultured with supernatants of lactic acid bacteria. 
A

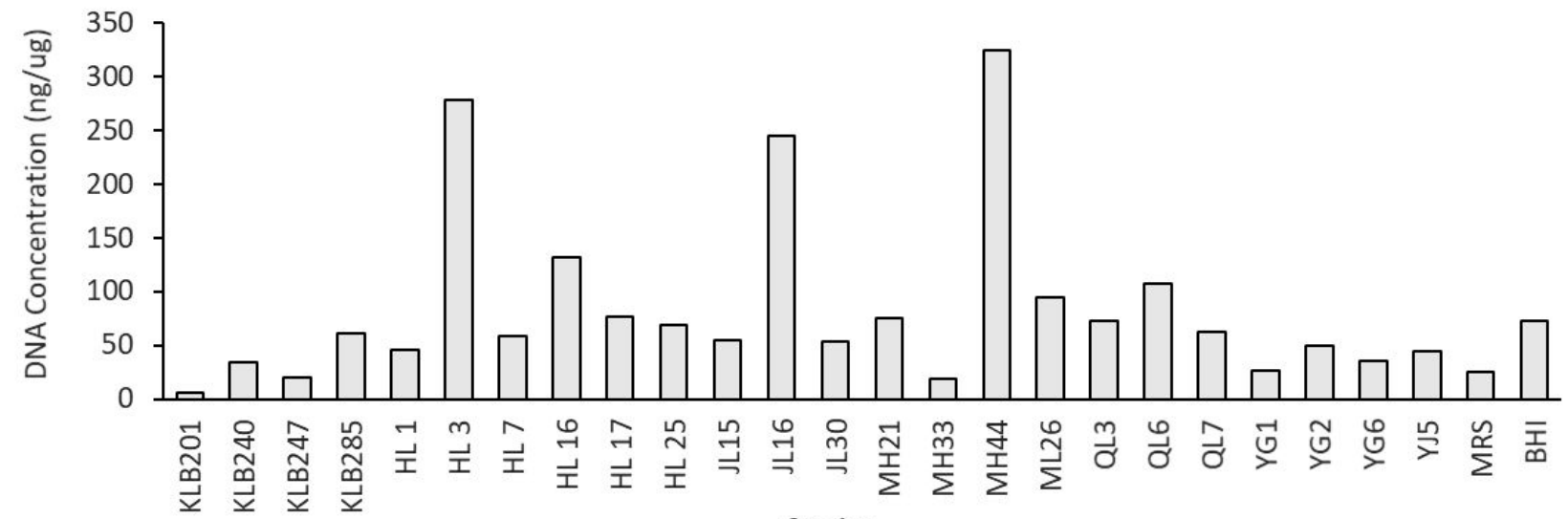

B

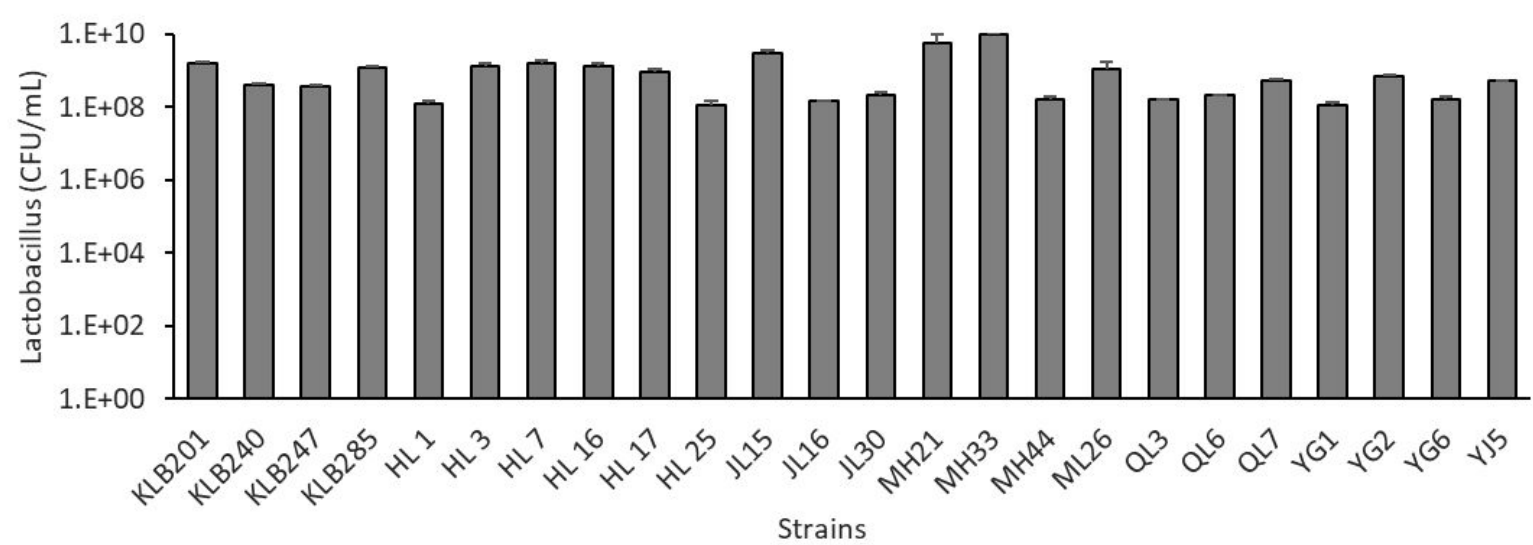

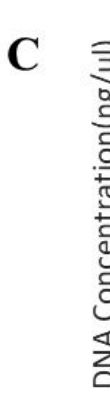

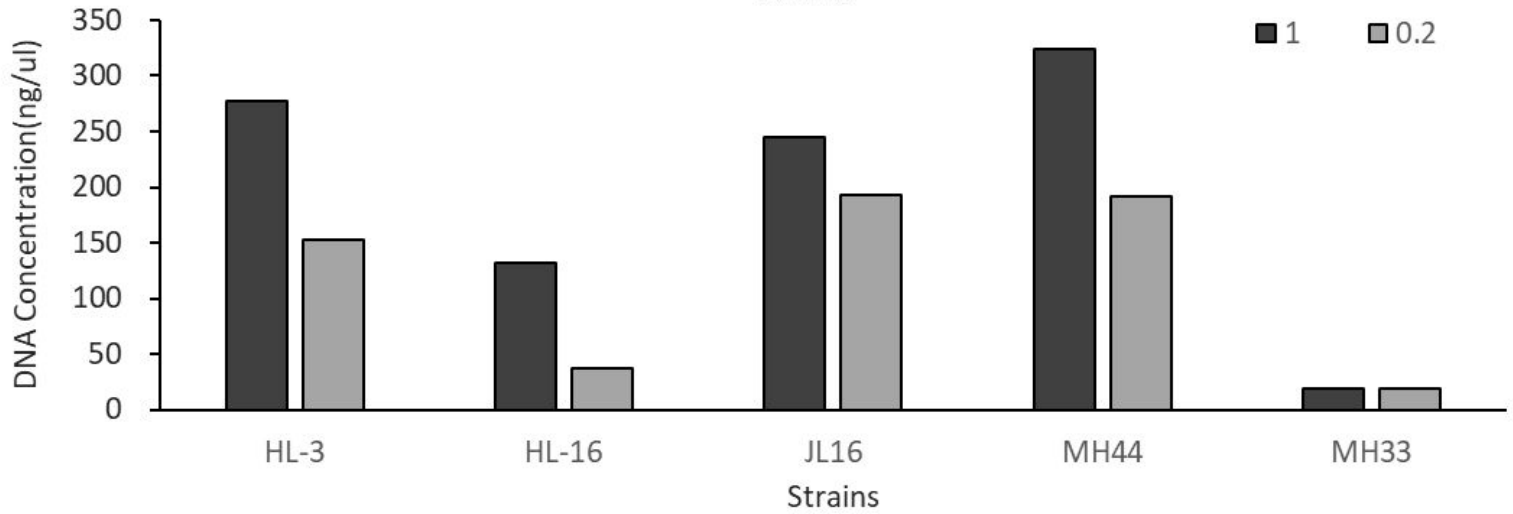

Figure 2. Growth of C. butyricum and lactic acid bacteria after co-culture. Quantification of the spo0A gene copy level in C. butyricum (A), cell growth of lactic acid bacteria (B), and quantification of spo0A gene copy level in C. butyricum according to the initial dose ratio of C. butyricum to lactic acid bacteria $(\mathrm{C})$.

C. butyricum. A standard curve for copy level variance was attempted to determine the concentration of C. butyricum. In Figure 2A, 24 Lactobacillus strains were co-cultured to examine their effectiveness in regard to the growth of C. butyricum. A growth acceleration of greater than 3 -fold was observed in co-cultures containing the HL3, JL16, and MH44 strains. The growth of 2-fold increase was observed in case of HL16. After the culture process, bacterial enumeration of LAB was also performed; however, no significant correlations were observed (Figure 2B). This suggests that the growth of C. butyricum could be affected by complicated factors, including the growth rate and the concentration of LAB.

To examine the initial mixing ratio between $C$. butyricum and $\mathrm{LAB}$, the ratio of $\mathrm{LAB}$ and C. butyricum was adjusted to $0.2: 1$. We observed that the copy level of the spoOA gene was reduced when the ratio was 0.2:1 (Figure 2C). MH33 was used as a control group. Relative disproportions were observed where HL3 $(45 \%, 152.7 \mathrm{ng} / \mu \mathrm{L})>\operatorname{HL} 16(72.1 \%, 36.8 \mathrm{ng} / \mu \mathrm{L})>\mathrm{JL} 16$ $(21.3 \%, 192.3 \mathrm{ng} / \mu \mathrm{L})>\mathrm{MH} 44(40.8 \%, 191.8 \mathrm{ng} / \mu \mathrm{L})$. The clear effectiveness was observed in co-cultures containing the JL16 
and MH44 strains. With the help of 16S sequencing analysis, JL16 and MH44 were identified to Lactobacillus brevis and Lactobacillus parabuchneri, respectively.

\subsection{Expression of the butyric acid production gene of C. butyricum in co-culture with Lactobacillus spp.}

The primer sequences of $b u k$ and $r e c A$ genes are listed in Table 2. It was expected that analyzing the buk gene provides the clues regarding butyrate production by $C$. butyricum, while recA gene expresses as a housekeeping gene. Here, two cases of MRS culture (without bacteria) and MH33 culture were selected and compared to the two other cases of JL16 and MH44 cultures (Figure 3). When compared to MRS culture, JL16 and MH44 exhibited 1.6-fold and 1.2-fold higher concentrations of the buk gene, respectively. While, MH33 culture exhibited a 20\% reduction in the number of buk genes compared to that in the MRS culture.

\subsection{Characterization of LAB for probiotics}

Bacterial enumeration was performed after JL16 and MH44 were cultured in different acidic conditions (Figure 4A). For JL16, a live number of approximately $10^{7}(\mathrm{pH} 2)$ was reduced to $10^{4}(\mathrm{pH} 3)$ and $10^{2}(\mathrm{pH} 2.5) \mathrm{CFU} / \mathrm{mL}$ under these experimental conditions. When MH44 was cultured in acidic conditions ( $\mathrm{pH} 2$ ), the numbers were reduced by approximately $10^{3}$. However, MH44 barely survived at the same level when the $\mathrm{pH}$ ranged from 2.5 to 3 .

The resistance behavior of JL16 and MH44 to the bile salts was measured and is presented in Figure 4B. The results are presented as the survival rates based on the reference state $(0 \%)$. Both JL16 and MH44 possessed improved rates in response to $0.3 \%$ exposure compared to those in response to $1.0 \%$ exposure. The survival rates for JL16 and MH44 and were $43 \%$ and 85\%, respectively, when they were evaluated in the presence of $0.3 \%$ bile salt. For $1.0 \%$ bile salt, the survival rates decreased to $36 \%$ for JL16 and 21\% for MH44.

As an in vitro test, auto-aggregation was substantially examined to evaluate the capability of biofilm formation. Both JL16 and MH44 exhibited rapid aggregation values of $87.8 \%$ for JL16 and $96.4 \%$ for MH44 in $5 \mathrm{hr}$. A freeze-drying technique is commonly used in the process of probiotic production, and this technique often harms these probiotics and limits their survival. The survival rates may rapidly decrease after the freeze-drying process. The survival rates of JL16 and MH44 were determined to $46 \%$ and $41 \%$, respectively.

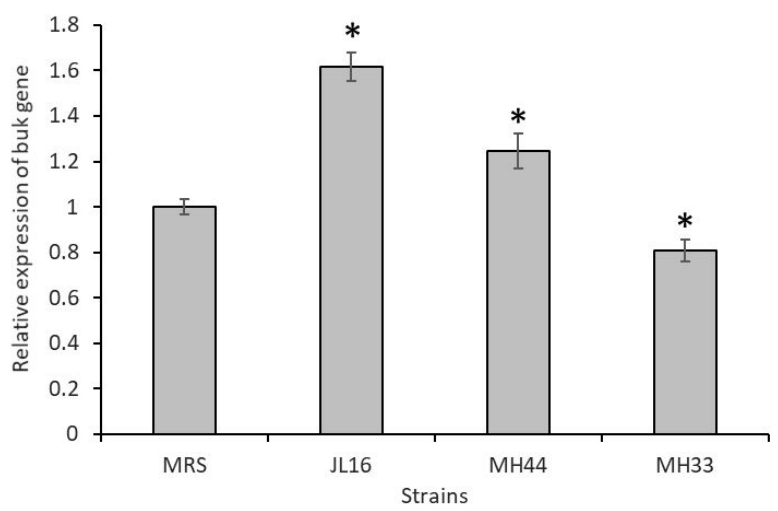

Figure 3. Relative expression of the buk gene in C. butyricum in the absence (MRS only) and presence of Lactobacillus strains (MH44, JL16 and MH33). Error bars indicate SEM; ${ }^{\star} \mathrm{P}<0.05$ vs. MRS group.
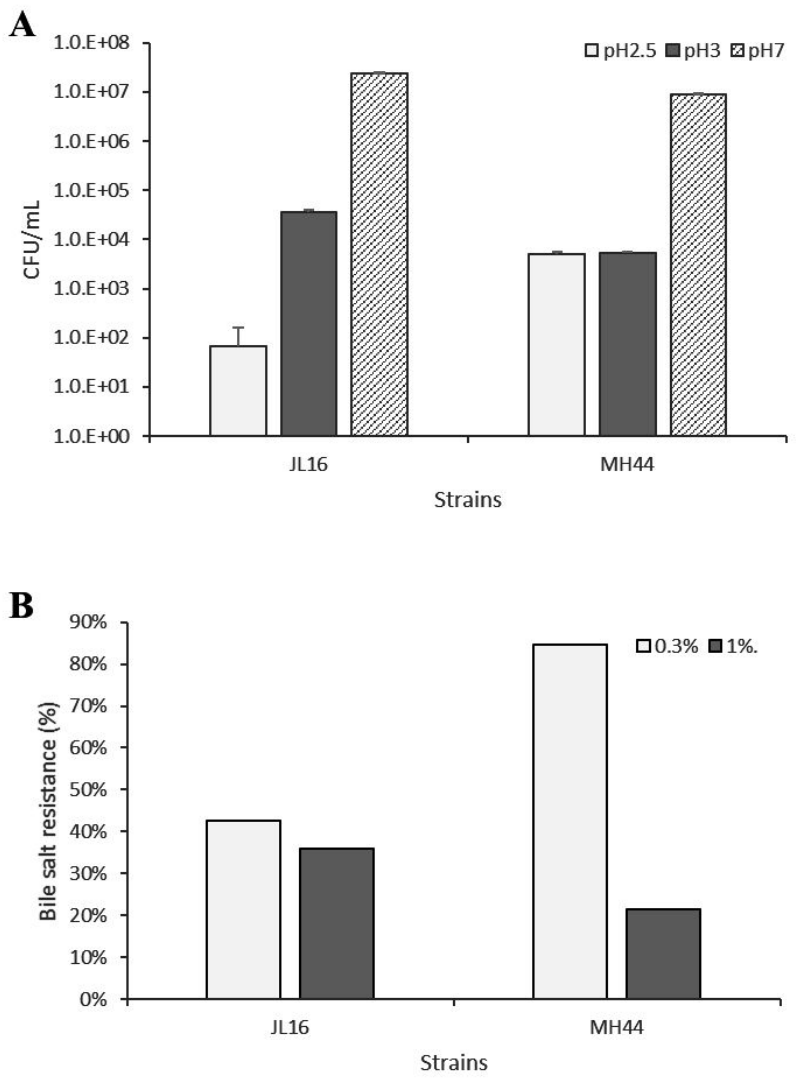

Figure 4. Two resistant behaviors of the MH44 and JL16 strains. Acid resistance (A) and bile resistance (B).

Table 2. C. butyricum genes examined by qPCR in this study.

\begin{tabular}{ccc}
\hline Primer & Sequence $\left(5^{\prime}\right.$ to 3') & Reference \\
\hline RTSpo0A_Fw & AGTGCTCCAACAATACAAGA & This study \\
RTSpo0A_Rv & AATATGAGCAGGTACACCG & Vital et al. (2013) \\
G_buk_F & TGCTGTWGTTGGWAGAGGYGGA & This study \\
G_buk_R & GCAACIGCYTTTTGATTTAATGCATGG \\
recA-fw & GCAGAGCATGCATTAGATCCT \\
recA-rv & GAATCTCCCATTTCCCCTTC & \\
\hline
\end{tabular}




\section{Discussion}

In literature, C. butyricum in combination with Lactobacillus spp. improved some factors in the animals such as promotion in intestinal functions, the stimulation of antioxidant pathway in combination with an effective reduction of lipid levels in its serum (Long et al., 2018), and effectiveness in curing acute colitis in a rat (Wang et al., 2018a). In this study, 2 LAB exhibited the potential that could enhance the probiotic functions of $C$. butyricum and identified L. brevis JL16 and L. parabuchneri MH44. L. brevis and L. parabuchneri are classified as obligate heterofermentative, where they convert sugars with 6 carbons to lactic acid, acetic acid, $\mathrm{CO}_{2}$, and two species that often occur in Kimchi and cheese (Coton et al., 2008; Park et al., 2016). A previous study indicated that $L$. brevis was effective in production of $\gamma$-aminobutyric acid, and it has been reported that $L$. brevis may be applicable to oral healthcare (Fang et al., 2018). In bacterial butyrate metabolism, butyrate kinase is recognized as one of the key enzymes in the pathway that produces butyrate (Chai et al., 2019). Butyrate-producing bacteria such as C. butyricum convert carbohydrates to butyryl-CoA through several processes, and butyryl-CoA is finally converted to butyrate through two channels (Esquivel-Elizondo et al., 2017). The key enzymes in these two channels are butyrate kinase and butyryl-CoA:acetate CoA transferase, respectively. Butyryl-CoA:acetate CoA transfer occurs in the presence of acetate. Meanwhile, Equivel-Elizondo et al. speculated that one of the two primary channels of butyrylCoA:acetate CoA transfer may not represent the main butyrate production route. When they compared the gene expression levels of the two major enzymes that mediated each response, they predicted that the expression of butyryl-CoA:acetate CoA transferase would remain relatively low in both batch culture and continuous culture. Thereafter, our comparison of the gene expression of butyrate kinase appears to be more reliable than that from butyryl-CoA:acetate CoA transferase, as butyrate production was more accurately predicted. It has also been reported the interchanges of chemicals were possible between different species of bacteria (Louis et al., 2004; Detman et al., 2019). For example, one of these nutrient-based interactions between bacteria can produce lactate, and another neighboring species of bacteria can consume lactate to produce butyrate. In literature, it was reported that $C$. butyricum can consume lactate and produce butyrate (Louis et al., 2004). The pathway responsible for generating butyrate requires the presence of two enzymes, butyrate kinase and butyryl-CoA:acetate CoA transferase. It is known that numerous steps are involved in the conversion from lactate to butyrate (Detman et al., 2019).

It is important to maintain a higher survival rate of probiotics when they enter the intestines. The first obstacle to survival occurs in a stomach where the $\mathrm{pH}$ is estimated to be 2 , although the $\mathrm{pH}$ can increase to approximately 2.5 to 3 when food is present. It has been reported that Lactobacillus spp. possess innate resistance to mild acidic environments (Šeme et al., 2015; Wang et al., 2018b); however, some species are rapidly weakened when exposed to a strongly acidic environment ( $\mathrm{pH}<2$ ) (Jin et al., 1998). In other cases, the use of either encapsulation or adaptation pretreatment can increase the resistance of probiotics to an acidic environment. The second obstacle to probiotic survival is the exposure of these organisms to bile salt. Bile salts can easily destroy the walls of probiotic bacteria and induce antibiotic functions such as oxidation stress following damage to DNA (Ruiz et al., 2013; Oleinikova et al., 2020). It was reported that the initial concentration of bile salt was $2-1.5 \%$ within $1 \mathrm{~h}$ and then decreased to $0.3 \%$ (Noriega et al., 2004). In this study, the concentration effect of bile salt was examined in the range of $0.3-1.0 \%$. It has been reported that the inhibitive concentration of bile salt is the most influential factor for the survival of strains, despite the knowledge that these concentration ranges vary according to strains. As mentioned earlier, the major objective of probiotics would be their safe delivery to intestines where they can activate their functions. It was speculated that biofilm formation of probiotics would provide a favorable strategy for them to remain and to activate within intestines (Juárez Tomás et al., 2005). In this study, skim milk was used to protect and stabilize the cell membranes of both strains, as suggested in an earlier research paper (Carvalho et al., 2004). In other cases, the survival rates of the six strains were $62 \%-92 \%$ after freeze-drying. The addition of sugars to skim milk may enhance the survival rates based on previously published results (Juárez Tomás et al., 2009). Additionally, sugar may remove activated oxygen molecules during the thaw process by inducing the protective roles of cell collapse (Leslie et al., 1995).

\section{Conclusion}

Clostridium butyricum was co-cultured in the presence of supernatants of 249 lactic acid bacteria. The gene expression of butyrate kinase was evaluated to verify the growth stimulation of C. butyricum in the presence of Lactobacillus spp. It was determined that Lactobacillus brevis JL16 and Lactobacillus parabuchneri MH44 stimulated C. butyricum more effectively than did other strains. Meanwhile, the acidic tolerances of both JL16 and MH44 were not adequate in a strongly acidic environment and needed to be overcome for use as probiotics such as capsulation. Probiotics might eventually reach in the intestine and interact with the intestinal microbe. This study is the basic research about potential probiotics for use with $C$. butyricum and interaction with the intestinal microorganisms.

\section{Acknowledgement}

This research was funded by an Inha University research grant.

\section{References}

Carvalho, A. S., Silva, J., Ho, P., Teixeira, P., Malcata, F. X., \& Gibbs, P. (2004). Relevant factors for the preparation of freeze-dried lactic acid bacteria. International Dairy Journal, 14(10), 835-847. http:// dx.doi.org/10.1016/j.idairyj.2004.02.001.

Chai, L. J., Lu, Z. M., Zhang, X. J., Ma, J., Xu, P. X., Qian, W., Xiao, C., Wang, S. T., Shen, C. H., Shi, J. S., \& Zheng-Hong, X. (2019). Zooming in on butyrate-producing Clostridial consortia in the fermented grains of baijiu via gene sequence-guided microbial isolation. Frontiers in Microbiology, 10, 1397. http://dx.doi.org/10.3389/fmicb.2019.01397. PMid:31316481.

Coton, M., Berthier, F., \& Coton, E. (2008). Rapid identification of the three major species of dairy obligate heterofermenters Lactobacillus brevis, Lactobacillus fermentum and Lactobacillus parabuchneri by species-specific duplex PCR. FEMS Microbiology Letters, 284(2), 
150-157. http://dx.doi.org/10.1111/j.1574-6968.2008.01206.x. PMid:18510560.

Detman, A., Mielecki, D., Chojnacka, A., Salamon, A., Błaszczyk, M. K., \& Sikora, A. (2019). Cell factories converting lactate and acetate to butyrate: Clostridium butyricum and microbial communities from dark fermentation bioreactors. Microbial Cell Factories, 18(1), 36. http://dx.doi.org/10.1186/s12934-019-1085-1. PMid:30760264.

Esquivel-Elizondo, S., Ilhan, Z. E., Garcia-Peña, E. I., \& KrajmalnikBrown, R. (2017). Insights into butyrate production in a controlled fermentation system via gene predictions. mSystems, 2(4), e0005117. http://dx.doi.org/10.1128/mSystems.00051-17. PMid:28761933.

Fang, F., Xu, J., Li, Q., Xia, X., \& Du, G. (2018). Characterization of a Lactobacillus brevis strain with potential oral probiotic properties. BMC Microbiology, 18(1), 221. http://dx.doi.org/10.1186/s12866018-1369-3. PMid:30577728.

Hsiao, E. Y., McBride, S. W., Hsien, S., Sharon, G., Hyde, E. R., McCue, T., Codelli, J. A., Chow, J., Reisman, S. E., Petrosino, J. F., Patterson, P. H., \& Mazmanian, S. K. (2013). Microbiota modulate behavioral and physiological abnormalities associated with neurodevelopmental disorders. Cell, 155(7), 1451-1463. http://dx.doi.org/10.1016/j. cell.2013.11.024. PMid:24315484.

Jin, L. Z., Ho, Y. W., Abdullah, N., \& Jalaludin, S. (1998). Acid and bile tolerance of Lactobacillus isolated from chicken intestine. Letters in Applied Microbiology, 27(3), 183-185. http://dx.doi.org/10.1046/j.1472765X.1998.00405.x. PMid:9750324.

Juárez Tomás, M. S., Bru, E., Martos, G., \& Nader-Macías, M. E. (2009). Stability of freeze-dried vaginal Lactobacillus strains in the presence of different lyoprotectors. Canadian Journal of Microbiology, 55(5), 544-552. http://dx.doi.org/10.1139/W08-159. PMid:19483783.

Juárez Tomás, M. S., Zonenschain, D., Morelli, L., \& Nader-Macías, M. E. (2005). Characterization of potentially probiotic vaginal lactobacilli isolated from Argentinean women. British Journal of Biomedical Science, 62(4), 170-174. http://dx.doi.org/10.1080/096 74845.2005.11732706. PMid:16411376.

Kang, C. H., Shin, Y. J., Kim, Y. G., \& So, J. S. (2016). Isolation of Lactobacillus strains from shellfish for their potential use as probiotics. Biotechnology and Bioprocess Engineering; BBE, 21(1), 46-52. http:// dx.doi.org/10.1007/s12257-015-0518-x.

Kong, Q., He, G. Q., Jia, J. L., Zhu, Q. L., \& Ruan, H. (2011). Oral administration of Clostridium butyricum for modulating gastrointestinal microflora in mice. Current Microbiology, 62(2), 512-517. http:// dx.doi.org/10.1007/s00284-010-9737-8. PMid:20711781.

Kos, B., Šušković, J., Vuković, S., Šimpraga, M., Frece, J., \& Matošić, S. (2003). Adhesion and aggregation ability of probiotic strain Lactobacillus acidophilus M92. Journal of Applied Microbiology, 94(6), 981-987. http://dx.doi.org/10.1046/j.1365-2672.2003.01915.x. PMid:12752805.

Lee, H. I., Kim, M. H., Kim, K. Y., \& So, J. S. (2010). Screening and selection of stress resistant Lactobacillus spp. isolated from the marine oyster. Anaerobe, 16(5), 522-526. http://dx.doi.org/10.1016/j. anaerobe.2010.07.002. PMid:20633689.

Leslie, S. B., Israeli, E., Lighthart, B., Crowe, J. H., \& Crowe, L. M. (1995). Trehalose and sucrose protect both membranes and proteins in intact bacteria during drying. Applied and Environmental Microbiology, 61(10), 3592-3597. http://dx.doi.org/10.1128/aem.61.10.35923597.1995. PMid:7486995.

Liu, J., Sun, J., Wang, F., Yu, X., Ling, Z., Li, H., Zhang, H., Jin, J., Chen, W., Pang, M., Yu, J., He, Y., \& Xu, J. (2015). Neuroprotective effects of Clostridium butyricum against vascular dementia in mice via metabolic butyrate. BioMed Research International, 2015, 412946. http://dx.doi.org/10.1155/2015/412946. PMid:26523278.
Long, M., Yang, S., Li, P., Song, X., Pan, J., He, J., Zhang, Y., \& Wu, R. (2018). Combined use of C. butyricum Sx-01 and L. salivarius C-1-3 improves intestinal health and reduces the amount of lipids in serum via modulation of gut microbiota in mice. Nutrients, 10(7), 81. http:// dx.doi.org/10.3390/nu10070810. PMid:29937527.

Louis, P., Duncan, S. H., McCrae, S. I., Millar, J., Jackson, M. S., \& Flint, H. J. (2004). Restricted distribution of the butyrate kinase pathway among butyrate-producing bacteria from the human colon. Journal of Bacteriology, 186(7), 2099-2106. http://dx.doi.org/10.1128/ JB.186.7.2099-2106.2004. PMid:15028695.

Noriega, L., Gueimonde, M., Sánchez, B., Margolles, A., \& de los Reyes-Gavilán, C. G. (2004). Effect of the adaptation to high bile salts concentrations on glycosidic activity, survival at low $\mathrm{pH}$ and cross-resistance to bile salts in Bifidobacterium. International Journal of Food Microbiology, 94(1), 79-86. http://dx.doi.org/10.1016/j. ijfoodmicro.2004.01.003. PMid:15172487.

Oleinikova, Y., Amangeldi, A., Yelubaeva, M., Alybaeva, A., Amankeldy, S., Saubenova, M., Chizhaeva, A., Aitzhanova, A., \& Berzhanova, R. (2020). Immobilization effects of wheat bran on enhanced viability of dairy starters under acid and bile salts stresses. Applied Food Biotechnology, 7(4), 215-223.

Park, H., Shin, H., Lee, K., \& Holzapfel, W. (2016). Autoinducer-2 properties of kimchi are associated with lactic acid bacteria involved in its fermentation. International Journal of Food Microbiology, 225, 38-42. http://dx.doi.org/10.1016/j.ijfoodmicro.2016.03.007. PMid:26977818.

Phuoc, T. L., \& Jamikorn, U. (2017). Effects of probiotic supplement (Bacillus subtilis and Lactobacillus acidophilus) on feed efficiency, growth performance, and microbial population of weaning rabbits. Asian-Australasian Journal of Animal Sciences, 30(2), 198-205. http:// dx.doi.org/10.5713/ajas.15.0823. PMid:27165020.

Rivera-Chávez, F., Zhang, L. F., Faber, F., Lopez, C. A., Byndloss, M. X., Olsan, E. E., Xu, G., Velazquez, E. M., Lebrilla, C. B., Winter, S. E., \& Bäumler, A. J. (2016). Depletion of butyrate-producing clostridia from the gut microbiota drives an aerobic luminal expansion of Salmonella. Cell Host \& Microbe, 19(4), 443-454. http://dx.doi. org/10.1016/j.chom.2016.03.004. PMid:27078066.

Ruiz, L., Margolles, A., \& Sánchez, B. (2013). Bile resistance mechanisms in Lactobacillus and Bifidobacterium. Frontiers in Microbiology, 4, 396. http://dx.doi.org/10.3389/fmicb.2013.00396. PMid:24399996.

Šeme, H., Gjuračić, K., Kos, B., Fujs, Š., Štempelj, M., Petković, H., Šušković, J., Bogovič Matijašić, B., \& Kosec, G. (2015). Acid resistance and response to $\mathrm{pH}$-induced stress in two Lactobacillus plantarum strains with probiotic potential. Beneficial Microbes, 6(3), 369-379. http://dx.doi.org/10.3920/BM2014.0069. PMid:25380802.

Stilling, R. M., van de Wouw, M., Clarke, G., Stanton, C., Dinan, T. G., \& Cryan, J. F. (2016). The neuropharmacology of butyrate: the bread and butter of the microbiota-gut-brain axis? Neurochemistry International, 99, 110-132. http://dx.doi.org/10.1016/j.neuint.2016.06.011. PMid:27346602.

Sun, J., Ling, Z., Wang, F., Chen, W., Li, H., Jin, J., Zhang, H., Pang, M., Yu, J., \& Liu, J. (2016). Clostridium butyricum pretreatment attenuates cerebral ischemia/reperfusion injury in mice via anti-oxidation and anti-apoptosis. Neuroscience Letters, 613, 30-35. http://dx.doi. org/10.1016/j.neulet.2015.12.047. PMid:26733300.

Takahashi, T., Taguchi, H., Yamaguchi, H., Osaki, T., Komatsu, A., \& Kamiya, S. (2004). The effect of probiotic treatment with Clostridium butyricum on enterohemorrhagic Escherichia coli O157:H7 infection in mice. FEMS Immunology and Medical Microbiology, 41(3), 219-226. http://dx.doi.org/10.1016/j.femsim.2004.03.010. PMid:15196571. 
Tian, T., Xu, B., Qin, Y., Fan, L., Chen, J., Zheng, P., Gong, X., Wang, H., Bai, M., Pu, J., Lu, J., Zhou, W., Zhao, L., Yang, D., \& Xie, P. (2019). Clostridium butyricum miyairi 588 has preventive effects on chronic social defeat stress-induced depressive-like behaviour and modulates microglial activation in mice. Biochemical and Biophysical Research Communications, 516(2), 430-436. http://dx.doi.org/10.1016/j. bbrc.2019.06.053. PMid:31227215.

Vital, M., Penton, C. R., Wang, Q., Young, V. B., Antonopoulos, D. A., Sogin, M. L., Morrison, H. G., Raffals, L., Chang, E. B., Huffnagle, H. B., Schmidt, T. M., Cole, J. R., \& Tiedje, J. M. (2013). A gene-targeted approach to investigate the intestinal butyrate-producing bacterial community. Microbiome, 1(1), 8. http://dx.doi.org/10.1186/20492618-1-8. PMid:24451334.

Wang, Y., Gu, Y., Fang, K., Mao, K., Dou, J., Fan, H., Zhou, C., \& Wang, H. (2018a). Lactobacillus acidophilus and Clostridium butyricum ameliorate colitis in murine by strengthening the gut barrier function and decreasing inflammatory factors. Beneficial Microbes, 9(5), 775-787. http://dx.doi.org/10.3920/BM2017.0035. PMid:30014710.

Wang, C., Cui, Y., \& Qu, X. (2018b). Identification of proteins regulated by acid adaptation related two component system HPK1/RR1 in Lactobacillus delbrueckii subsp. bulgaricus. Archives of Microbiology, 200(9), 1381-1393. http://dx.doi.org/10.1007/s00203-018-1552-9. PMid:30022229.

Yasueda, A., Mizushima, T., Nezu, R., Sumi, R., Tanaka, M., Nishimura, J., Kai, Y., Hirota, M., Osawa, H., Nakajima, K., Mori, M., \& Ito, T. (2016). The effect of Clostridium butyricum MIYAIRI on the prevention of pouchitis and alteration of the microbiota profile in patients with ulcerative colitis. Surgery Today, 46(8), 939-949. http:// dx.doi.org/10.1007/s00595-015-1261-9. PMid:26510664. 